\section{Imagens e concepções de adolescentes moradores de zonas rurais sobre saúde}

\author{
Health-related images and concepts among \\ adolescents living in rural areas of Brazil \\ Imágenes y concepciones de adolescentes que \\ viven en zonas rurales acerca de la salud
}

\begin{abstract}
1 Faculdade de Farmácia, Odontologia e Enfermagem, Universidade Federal do Ceará, Fortaleza, Brasil.

Correspondência A. G. M. Costa Programa de Pós-graduação em Enfermagem, Faculdade de Farmácia, Odontologia e Enfermagem, Universidade Federal do Ceará.

Rua André Dall'Olio 800, apto. 500, Fortaleza, CE 60175-195, Brasil. annygiselly@yahoo.com
\end{abstract}

\begin{abstract}
The objective of this study was to describe healthrelated images and concepts among adolescents living in rural areas of Brazil, using photography. This was a qualitative community-based participatory study that used the photovoice method for data collection with groups of teenagers. Over a four-month period, 26 participants identified health problems in the rural community, took photographs, and reflected critically on the local reality. The adolescents presented pictures and stories that they organized into research themes and categories, representing inadequate living conditions for appropriate socioeconomic and cultural development and limiting the opportunities for change in this community. The study proved to be a positive health education strategy, involving young people in the community's health and maximizing the voice of teenagers as protagonists in their own history.
\end{abstract}

Community-Based Participatory Research; Photography; Adolescent
Anny Giselly Milhome da Costa 1 Neiva Francenely Cunha Vieira 1 Fabiane do Amaral Gubert 1 Adriana Gomes Nogueira Ferreira 1 Ligia Fernandes Scopacasa 1 Patrícia Neyva da Costa Pinheiro ${ }^{1}$

\section{Resumo}

O presente estudo teve como objetivo descrever as concepções de adolescentes moradores de zonas rurais sobre saúde por meio da fotografia. Estudo qualitativo, do tipo pesquisa participativa baseada na comunidade, que utilizou o método fotovoz para coleta dos dados com grupos de adolescentes. Durante um período de quatro meses, 26 participantes identificaram problemas de saúde da comunidade rural, captaram imagens e refletiram criticamente acerca da realidade. Os adolescentes apresentaram imagens e histórias que foram organizadas em temas $e$ categorias da investigação que representaram condições de vida inadequadas para o desenvolvimento socioeconômico e cultural, limitando as oportunidades de mudança desta comunidade. O estudo evidenciou uma estratégia de educação em saúde positiva, que envolveu os adolescentes na saúde coletiva da comunidade e potencializou a voz do jovem como protagonista de sua história.

Pesquisa Participativa Baseada na Comunidade; Fotografia; Adolescente 


\section{Introdução}

As comunidades rurais brasileiras vivenciam problemas de saúde relacionados ao crescente processo de urbanização do território e migração 1. Os principais desafios para a promoção da saúde dos adolescentes do campo envolvem questões econômicas e ambientais específicas que conduzem a adolescência de um período de oportunidades para o ser saudável e produtivo para uma fase de vulnerabilidade e riscos 2 .

No trabalho com comunidades rurais, a promoção da saúde está diretamente ligada à educação para a mudança social e formação de indivíduos conscientes de seus direitos e deveres 3 , assim a educação em saúde é pilar da atuação de médicos e enfermeiros nos três níveis de complexidade do Sistema Único de Saúde (SUS) ${ }^{4}$.

O objetivo deste estudo foi descrever as concepções de saúde de adolescentes moradores de zona rural, identificando os principais problemas de saúde locais para reorientação de práticas educativas e políticas públicas locais.

\section{Métodos}

Pesquisa participativa baseada na comunidade que utilizou o método fotovoz para coleta dos dados 5,6,7. A pesquisa participativa baseada na comunidade integra abordagem qualitativa, pesquisa-ação e pesquisa participante no cenário cultural de vida dos informantes ${ }^{8}$. O fotovoz é um recurso metodológico por meio do qual as pessoas utilizam câmeras fotográficas para documentar suas realidades de vida e saúde 5,6,7.

A pesquisa foi desenvolvida numa zona rural da Região Nordeste do Brasil, com 1.181 habitantes, sendo $139(11,7 \%)$ adolescentes entre 12 a 18 anos. As práticas econômicas da comunidade eram baseadas na agricultura de subsistência, extração mineral, artesanato e pequeno comércio. Cerca de 370 famílias habitavam a região, sendo que 197 (60\%) destas estavam em situação de vulnerabilidade social com renda per capita de até $\mathrm{R} \$ 140,009$.

Cerca de 80 adolescentes da escola local foram convidados a participar da pesquisa. Após sensibilização e divulgação do projeto fotovoz ocorreram 55 inscrições voluntárias. De acordo com critérios de inclusão da pesquisa, a amostra final foi constituída por 26 adolescentes agrupados em dois grupos de 13 participantes.

Cada grupo reuniu-se semanalmente com os facilitadores, durante um período de quatro meses, seguindo as etapas do método: (1) problematização; (2) seleção de temas iniciais para fotografar; (3) treinamento para uso da câmera e aspectos éticos; (4) fotografia; (5) seleção das imagens para discussão; (6) contextualização e escritura de histórias de cada fotografia; (7) codificação; (8) soluções para os problemas; (9) divulgação e sensibilização da comunidade, gestores, mídia, pesquisadores e; (10) avaliação.

Os adolescentes registraram os dados em fotografias e histórias escritas elaboradas a partir do processo de reflexão crítica em resposta às questões SHOWeD do fotovoz 5,7: "O que você vê nesta imagem?" [What do you See here?], "O que realmente está acontecendo?" [What is really $\mathrm{Ha}$ ppening?], “Qual relação com nossas vidas?” [How does this relate to Our lives?], "Por que esta situação existe?" [Why does this problem or strength exist?] e "O que podemos fazer para melhorá-la?" [What can we Do about it?].

Os pesquisadores utilizaram diário de campo e transcrição de narrativas orais e agruparam as fotografias em duas categorias: (1) alimentação do adolescente: boa alimentação e má alimentação; (2) saúde do adolescente: atendimento de saúde, doenças e pobreza. As imagens apresentadas em cada categoria foram consideradas mais relevantes durante a exposição fotográfica final do projeto. As narrativas acerca das imagens foram transcritas originalmente pelos adolescentes. A pesquisa foi aprovada pelo Comitê de Ética da Universidade Federal do Ceará, protocolo no 09/09.

\section{Resultados}

Os problemas de saúde identificados pelos grupos foram: má alimentação, precário atendimento de saúde, doenças e pobreza da comunidade.

Alimentação do adolescente: boa alimentação e má alimentação

Os adolescentes fotografaram alimentos e situações que representaram uma boa ou má alimentação na comunidade. A diferença entre estas foi apresentada como consumir frutas e vegetais, feijão com arroz e carne, ou comer doces e guloseimas. Nas discussões grupais predominou o consumo de alimentos pouco saudáveis entre os adolescentes.

Na Figura 1 podemos ver a imagem de um prato de salada em cima de uma mesa. "Esta imagem significa algo bom porque nós temos que se alimentar bem, e saladaé um bom prato. Esteéum problema que muito jovem tem, em comer salada de verduras. Esse problema existe, porque algumas pessoas deixam de se alimentar bem, para comer besteiras. (...) eu acho que nós podemos alertar as pessoas o que faz mal à saúde". (P.4, 14 anos). 


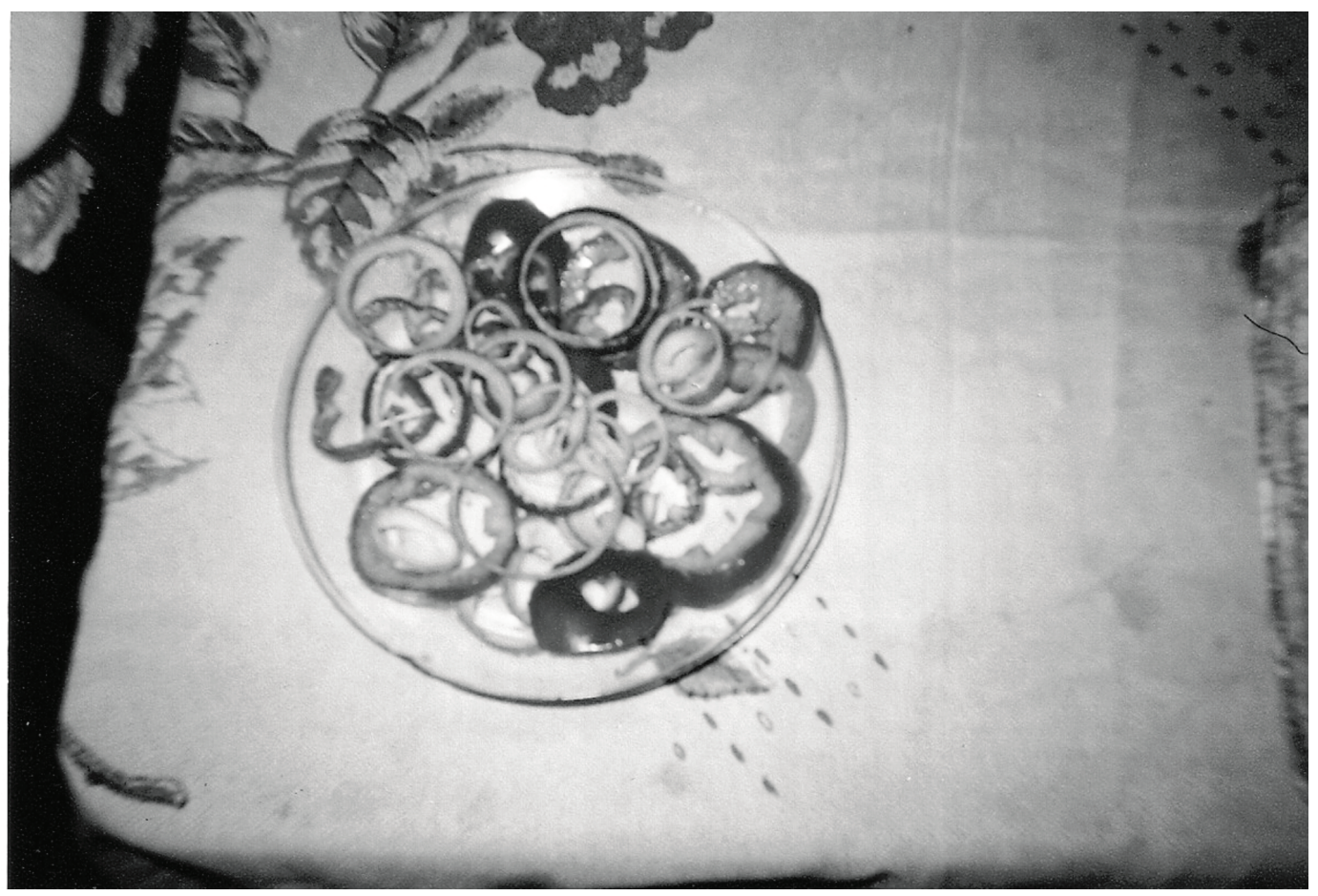

Saúde do adolescente: atendimento de saúde, doenças e pobreza

Os adolescentes enfatizaram a falta de infraestrutura adequada para o funcionamento da unidade básica de saúde (UBS). Na Figura 2 observa-se uma estrutura física danificada e uma narrativa voltada à dificuldade de atendimento médico. Os participantes refletiram acerca da saúde voltada para doença e pobreza local.

"A saúde está em primeiro lugar, mas o poder público não faz nada para a saúde, as pessoas estão doentes: a gente para se consultar, tem que ir de madrugada para pegar uma ficha para se consultar (...) os governantes fizeram muitas coisas em lazer na cidade, mas na saúde eles não fizeram nada". (P.6, 17 anos).

Sobre a Figura 3 temos a seguinte fala: "Falta tudo para pessoas que não têm educação, lazer, proteção, etc. Um dos responsáveis por esses fatos é a falta de cursos profissionalizantes, baixa escolaridade isso é uma das causas de falta de trabalho na cidade. E desse jeito a pobreza vai se alimentando cada vez mais". (P.17, 12 anos).

\section{Discussão}

A fotografia apresentou-se como "o novo" na comunidade rural ao revisitar a realidade local por meio das lentes, assim como na pesquisa Youth Participatory Action Research (YPAR) a fotografia foi um elemento crítico fundamental para a participação ativa dos jovens 10 .

Para os participantes, a alimentação é responsável pelo "ser saudável" e reconhecem o elevado consumo de alimentos industrializados, com baixo teor nutritivo na comunidade. Estudo com adolescentes brasileiros revelou perfil alimentar preocupante entre os jovens rurais com consumo insuficiente de frutas/vegetais e ingestão excessiva de alimentos como refrigerantes e doces, colocando-os como um grupo de risco ${ }^{11}$.

A prevenção da obesidade juvenil em comunidades rurais pode ser realizada por meio do método fotovoz, pois as fotografias e histórias envolvem pais e membros da comunidade para a necessidade de mudança e desperta a liderança dos adolescentes frente às políticas públicas de alimentação saudável 12 . 

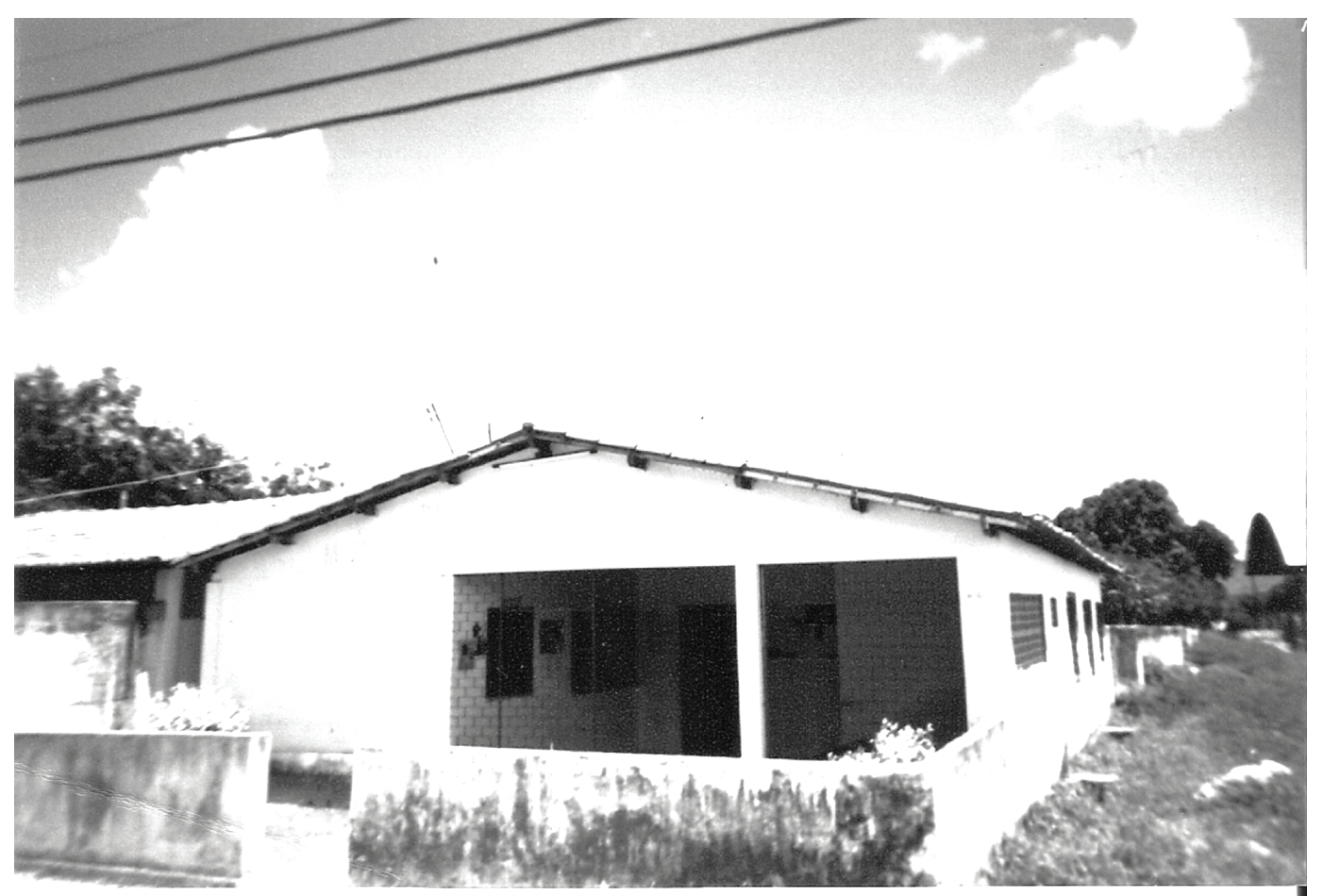

As concepções de saúde dos adolescentes revelaram iniquidades e dificuldades de acesso ao atendimento. Os grupos reconheceram os problemas de saúde pública e revelaram desejo de mudanças, mas sentiram-se despreparados para reivindicar seus direitos 13 .

As imagens provocaram sentimentos de frustração com os governantes, todavia identificaram sugestões de melhorias: reforma da unidade, melhorias no atendimento médico. A ausência ou ineficácia de políticas públicas para a juventude deve-se desconsideração dos jovens detentores de identidade própria e da diversidade de juventudes 14 .

A visão de saúde dos adolescentes do espaço rural está relacionada às condições socioeconômicas que vivenciam, necessitando assim de políticas de atenção à saúde que considerem o contexto no qual estão inseridos, restringindose ao atendimento clínico, o que corrobora uma concepção reduzida de saúde 15 .

A pobreza é também uma realidade social da comunidade que influencia a saúde dos adolescentes, pois corresponde à condição de insatis- fação de necessidades humanas básicas 16 . No Nordeste brasileiro, a frequência de pessoas em situação de pobreza é maior no meio rural que no urbano ${ }^{1}$. Os adolescentes relacionaram pobreza com falta de cuidados à saúde. A educação ambiental é base para a prevenção eficaz contra a contaminação do ar, água, alimentos e outros fatores de risco comum para a saúde, sendo imprescindível implantar ações na escola sobre os conceitos de saúde ambiental 17 .

O presente estudo evidenciou o fotovoz como uma estratégia positiva de educação em saúde para mudança social que pode ser utilizada pelos profissionais da saúde do SUS. As políticas públicas de saúde devem ser reorientadas para fortalecer o status socioeconômico e cultural das famílias rurais, considerando as evidências que quanto maior o status socioeconômico e cultural das famílias, maiores serão seus conhecimentos e investimentos na saúde dos filhos 18 . 


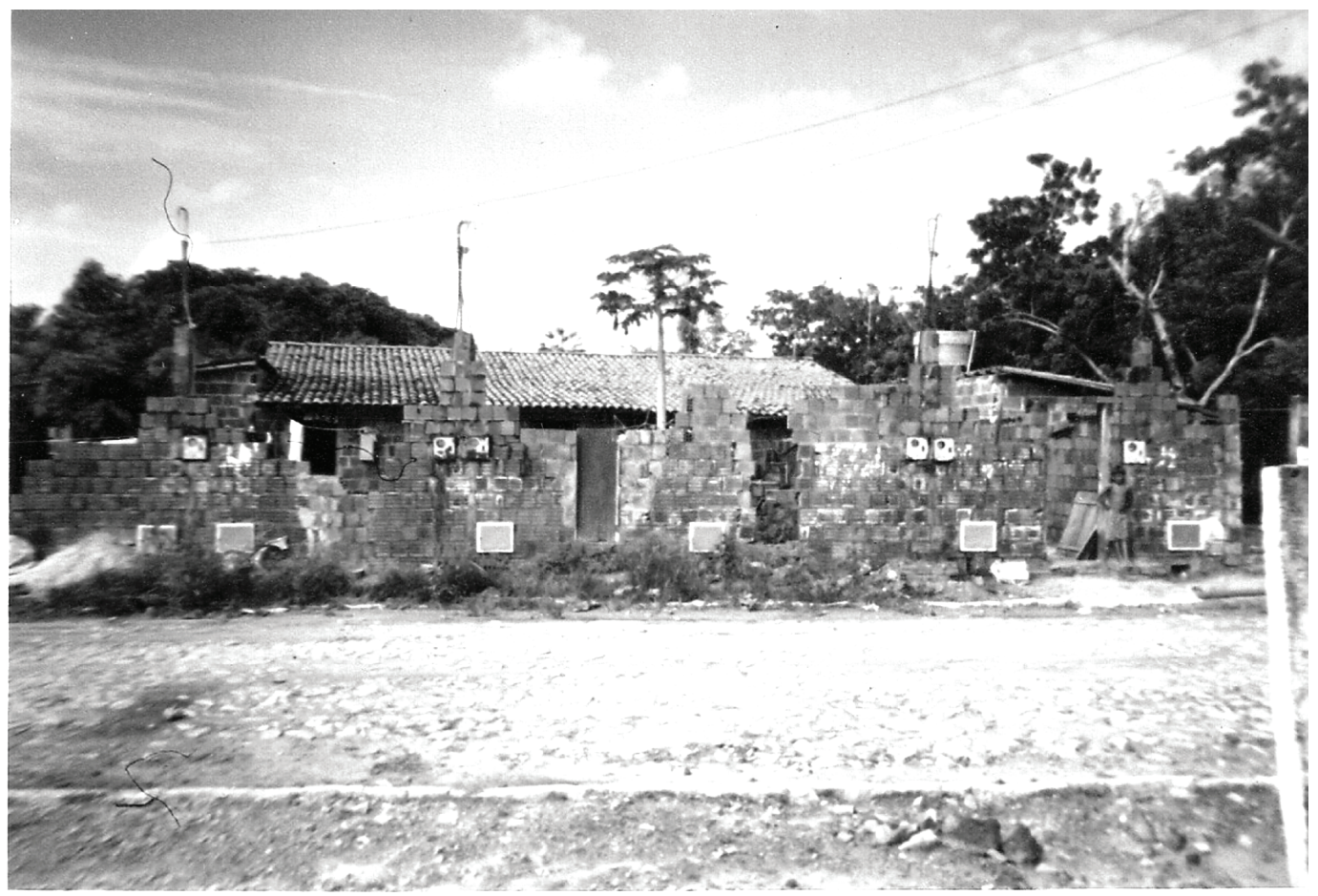

\section{Resumen}

El objetivo del estudio fue describir las concepciones de adolescentes que viven en zonas rurales sobre salud a través de la fotografía. Es una investigación participativa, basada en la comunidad, con enfoque cualitativo, que utilizó el método fotovoz para la recolección de datos con grupos de adolescentes. Durante un período de cuatro meses, 26 participantes identificaron los problemas de salud de la comunidad rural, capturaron imágenes y reflexionaron críticamente sobre la realidad. Los participantes presentaron imágenes e historias que fueron organizados por temas y categorías de investigación que representaron condiciones de vida inadecuadas para el desarrollo socioeconómico y cultural, que limita oportunidades de cambio en la comunidad. El estudio reveló una estrategia de educación en salud positiva, con la participación de jóvenes en la salud comunitaria y mejoría de la voz del joven protagonista de su historia.

Investigación Participativa Basada en la Comunidad; Fotografí; Adolescente

\section{Colaboradores}

A. G. M. Costa, N. F. C. Vieira e P. N. C. Pinheiro contribuíram com a concepção e projeto, análise e interpretação dos dados, redação do artigo, revisão crítica relevante do conteúdo intelectual e aprovação final da versão a ser publicada. F. A. Gubert, A. G. N. Ferreira e L. F. Scopacasa participaram na revisão crítica e redação final do manuscrito.

\section{Agradecimentos}

Ao CNPq pelo apoio à pesquisa. 


\section{Referências}

1. Peres F. Saúde, trabalho e ambiente no meio rural brasileiro. Ciênc Saúde Coletiva 2009; 14:19952004.

2. World Health Organization. Strengthening the health sector response to adolescent health and development. Geneva: World Health Organization; 2010.

3. Fernandes GCM, Boehs AE. Literature contributions to rural family nursing. Texto \& Contexto Enferm 2011; 20:803-11.

4. Moretti-Pires RO. Complexity in family healthcare and the training of future healthcare professionals. Interface Comun Saúde Educ 2009; 13:153-66.

5. Nykiforuk CIJ, Vallianatos H, Nieuwendyk LM Photovoice as a method for revealing community perceptions of the built and social environment Int J Qual Methods 2011; 10:103-24.

6. Wang CC, Yi WK, Tao ZW, Carovano K. Photovoice as a participatory health promotion strategy. Health Promot Int 1998; 13:75-86.

7. Wang C, Redwood-Jones YA. Photovoice ethics: perspectives from flint photovoice. Health Educ Behav 2001; 28:31-7.

8. Wallerstein M, Duran B. Community-based participatory research contributions to intervention research: the intersection of science and practice to improve health equity. Am J Public Health 2010; 100 Suppl 1:S40-6.

9. Instituto de Pesquisa Econômica Aplicada. Objetivos de desenvolvimento do milênio: relatório nacional de acompanhamento. Brasília: Instituto de Pesquisa Econômica Aplicada; 2010.
10. Smith L, Bratini L, Appio LM. "Everybody's teaching and everybody's learning": photovoice and youth counseling. J Couns Dev 2012; 90:3-12.

11. Enes CC, Pegolo GE, Silva MV. Hábitos alimentares de adolescentes residentes em áreas rurais da cidade de Piedade. Nutrire: Rev Soc Bras Aliment Nutr 2008; 33:99-110.

12. Nancy E. Findholt YL. Michael MM. Davis photovoice engages rural youth in childhood obesity prevention. Public Health Nurs 2011; 28:186-92.

13. Torres CA, Barbosa SM, Pinheiro PNC, Vieira NFC. Health and popular education with adolescents. Rev RENE 2010; 11:47-56.

14. Fundo das Nações Unidas para a Infância. O direito de ser adolescente: oportunidade para reduzir vulnerabilidades e superar desigualdades. Brasília: Fundo das Nações Unidas para a Infância; 2011.

15. Muza GM, Costa MP. Elementos para a elaboração de um projeto de promoção à saúde e desenvolvimento dos adolescentes: o olhar dos adolescentes. Cad Saúde Pública 2002; 18:321-8.

16. Gomes CN, Horta NC. Promoção de saúde do adolescente em âmbito escolar. Rev APS 2010; 13: 486-99.

17. Dobrowolski JW. Human ecology and interdisciplinary cooperation for primary prevention of environmental risk factors for public health. Przegl Lek 2007; 64 Suppl 4:35-41.

18. Borges A, Matos MG, Diniz JA. Processo adolescente e saúde positiva: âmbitos afectivo e cognitivo. Psicol Refl Crít 2011; 24:281-91.

Recebido em 23/Jan/2013

Versão final reapresentada em 27/Mar/2013

Aprovado em 24/Abr/2013 